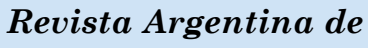

\section{Nueva sección de la Revista Argentina de Reumatología}

La Revista Argentina de Reumatología, publicación oficial de la Sociedad Argentina de Reumatología, ha seguido a lo largo de los años los avances de la especialidad en nuestro país y en el mundo. La revisión por pares ("peer review"), es uno de los pilares que la revista ha tenido en los últimos años editoriales y ha sido realizada por referentes en cada tema.

Para darle aún más interés y jerarquía a los trabajos publicados, consideramos apropiado la apertura a participar a otros profesionales que tengan opiniones o experiencias divergentes o que apoyen los trabajos publicados aportando una visión original o alguna información faltante y necesaria. Es por eso que evaluamos la necesidad de incorporar una nueva sección, tal como se encuentra en las grandes publicaciones internacionales: "Cartas al Editor".

Las cartas al editor se consideran para publicación (sujetas a edición y resumen) siempre que no contengan material que haya sido enviado o publicado en otro lugar.

Las cartas aceptadas para su publicación aparecerán impresas. Las cartas en referencia a un artículo de la revista no deben exceder las 175 palabras (sin incluir las referencias), y deben recibirse dentro de las tres semanas posteriores a la publicación de dicha edición de la revista.

Las cartas que no estén relacionadas con un artículo de la revista no deben exceder las 300 palabras (sin incluir las referencias).

No publicaremos agradecimientos en esta sección.

Para enviar una carta al editor se deberá entrar a la página web de la revista http://www.revistasar.org.ar/, entrar a "Envío de Artículos", y luego de logearse, marcar "Nuevo envío" y en la "Sección de la Revista" se deberá elegir: "Carta de Lectores".

Una carta no puede tener más de cinco referencias y una figura o tabla. Una carta puede ser firmada por no más de tres autores. La Revista imprimirá una afiliación institucional única o, si una afiliación institucional no está disponible, una dirección postal. Incluso si tiene múltiples afiliaciones, solo podrá incluir una.

Se deberán divulgar posibles conflictos de interés.

Se recibirá un acuse de recibo por correo electrónico del envío. También se dispondrá de un correo electrónico para envío de las Cartas al Editor en forma directa (revista@reumatologia.org.ar).

Esperamos poder contar con el valioso aporte de nuestros Lectores, Autores, Revisores y Miembros del Comité editorial para construir una sección dinámica que siga prestigiando la revista. 